\title{
The Importance of Male Partner Involvement for Women's Acceptability and Adherence to Female-Initiated HIV Prevention Methods in Zimbabwe
}

\author{
Elizabeth T. Montgomery • Ariane van der Straten • \\ Agnes Chidanyika - Tsungai Chipato • \\ Shabbar Jaffar $\cdot$ Nancy Padian
}

Published online: 16 September 2010

(C) The Author(s) 2010. This article is published with open access at Springerlink.com

\begin{abstract}
Enlisting male partner involvement is perceived as an important component of women's successful uptake of female-initiated HIV prevention methods. We conducted a longitudinal study among a cohort of 955 Zimbabwean women participating in a clinical trial of the effectiveness of a female-initiated HIV prevention method (the diaphragm and lubricant gel) to: (a) describe the extent to which women involved their male partners in the decision to use the study products, and (b) measure the effect perceived male partner support had on their acceptability and consistent use of these methods. Reported levels of male partner involvement in discussions and decisions regarding: joining the study, study activities, the outcome of HIV/STI test results, and product use were very high. In multivariate analyses, regular disclosure of study product use and partner approval for the
\end{abstract}

E. T. Montgomery $(\bowtie) \cdot$ A. van der Straten

Women's Global Health Imperative, RTI International,

San Francisco Project Office, San Francisco, CA, USA

e-mail: emontgomery@rti.org

E. T. Montgomery $\cdot$ S. Jaffar

Department of Epidemiology, London School of Hygiene and Tropical Medicine, Infectious Disease Epidemiology Unit, London, UK

A. van der Straten

Department of Medicine, Center for AIDS Prevention Studies, University of California San Francisco, San Francisco, CA, USA

A. Chidanyika $\cdot$ T. Chipato

University of Zimbabwe-University of California San Francisco Research Collaborative Programme in Women's Health, Harare, Zimbabwe

N. Padian

University of California, Berkeley, School of Public Health, Berkeley, CA, USA diaphragm and gel were significantly associated with women's acceptability and consistent use of the products; an essential component for determining efficacy of investigational prevention methods. These results support the need for more sophisticated measurement of how couples interact to make decisions that impact study participation and investigational product use as well as more rigorous adaptations and evaluations of existing strategies to involve male partners in female-initiated HIV prevention trials.

Keywords HIV prevention - Female-initiated methods . Zimbabwe Male involvement . Adherence .

Acceptability $\cdot$ Couples

\section{Introduction}

The majority of HIV infected persons live in sub-Saharan Africa: approximately 23 million out of a worldwide 33 million at the end of 2007 [1]. Within sub-Saharan Africa, women, especially young women, are disproportionately affected due to their biological and socio-cultural vulnerability [1]. To address this imbalance, extensive research has been directed towards the urgent need to identify female-initiated HIV prevention methods, such as vaginal microbicides and/or barrier methods that would enable women to protect themselves from disease acquisition while potentially overcoming the obstacles that they may face when negotiating use of male condoms.

Male partner support is perceived as an essential component of women's successful use of female-initiated methods in a research study context, and more generally, the involvement of men in women's reproductive health has been endorsed by multinational agencies [2-17]. However, the risks and benefits of partner involvement are 
not well understood, nor are effective strategies for engaging male partners in women's health well established. Studies that have taken the approach of enrolling couples to garner partner support have reported improvement in women's reproductive health outcomes as measured by decreased abortions and unplanned pregnancies in China [18]; modern contraceptive uptake in Ethiopia [19]; uptake of nevirapine to prevent mother-to-child transmission of HIV in Kenya [20]; increased safe sex behaviour and decreased HIV incidence following voluntary counselling and testing (VCT) for HIV in Africa and the US [21-26].

However, other observational studies have demonstrated the inverse: negative male involvement, as measured by relationship-level factors such as intimate partner violence, relationship power and decision-making, is associated with HIV risk among women [27-29]. Indeed, only a handful of studies have considered the potential adverse effects of involving men on women's health and empowerment, on relationships and family dynamics, or discussed its cost, difficulty, and possible lack of effect $[30,31]$. For example, in Zimbabwe following a nationwide social marketing campaign to involve men and promote joint decisionmaking among couples in family planning, men were more likely to consider themselves the primary decision-makers regarding family planning and parity [16]. Involving male partners in female-initiated HIV/STI prevention could similarly have the unintended effect of further disempowering women or putting them at risk for HIV: women's use of female-initiated products could "excuse" their male partners from condom use and reduce their responsibility for safe-sex, as has been anecdotally reported in Zimbabwe and Turkey [2, 9].

We conducted an ancillary study among Zimbabwean women participating in a multi-site clinical trial of the effectiveness of a female-initiated HIV prevention method (the diaphragm and lubricant gel) to describe the extent to which they involved their male partners in the decision to join the study and to use products. This is the first large study in the context of a phase III HIV prevention trial to systematically capture detailed prospective information about the role of the male partner in women's study participation and product use. We also examined the association among different aspects of male involvement with women's attitudes and behaviour regarding the use of female-initiated methods.

\section{Methods}

\section{Study Design}

This study was an ancillary study of the Methods for Improving Reproductive Health in Africa (MIRA) Study, an open-label, multisite phase III randomized, controlled trial measuring the effectiveness of the diaphragm and lubricant gel in preventing HIV and STI acquisition in Zimbabwe and two sites in South Africa [32]. This ancillary study, which began in Month 16 (of 40) of the main trial, was conducted among all the women enrolled at the Zimbabwe site, where a total of 1,916 MIRA participants (955 in the intervention arm) were included in the male involvement study for 12-24 months, depending on their enrolment date, from December 2004 through December 2006.

\section{Procedures}

The MIRA trial procedures and eligibility criteria are described in detail elsewhere [32]. Briefly, we enrolled sexually active, HIV-negative, non-pregnant women with no known allergy to latex and a healthy cervix, who were willing to follow the study protocol and give written informed consent. Women at the Zimbabwe site were recruited predominantly from well-baby clinics, community groups and through word-of-mouth, and invited to come to the study clinics for screening. Just under half (46\%) of the women who presented for screening were enrolled in the study; the majority $(60 \%)$ were ineligible because of HIV-positive status. All women randomized into MIRA at the Zimbabwe site were automatically enrolled in the male involvement study, and no additional consenting procedures were required as the scope of enquiry fell into that already approved for the study by the relevant Institutional Review Boards.

During the main MIRA enrolment informed consent procedures, women were told that they could invite their male partners to come to the clinic for free counselling and testing for STIs and HIV. During risk reduction and product counseling at the enrolment and follow-up visits, counsellors discussed male partner support and product use negotiation, and the invitation for male partners to come to the study clinic for information or counselling and testing was reiterated, however it was made clear that this was the woman's choice and not a study requirement. Because this study was nested within a standardized clinical trial, and more overt engagement of male partners at a single site might have biased the main trial results, we did not include any kind of formal outreach, promotional activities or intervention to involve male partners, although clinic staff kept records of male partner clinic attendance (for any service).

As part of the main study, participants completed an Audio Computer-assisted Self-interview (ACASI) interview about sexual behaviour and product use at enrolment and all quarterly follow-up visits, and an Acceptability Questionnaire was administered at Month 3 and at the Exit 
visit via face-to-face interview. At Months 3 and 12, female study participants received an interviewer-administered "male partner involvement" questionnaire designed for this study.

\section{Measures}

\section{Male Involvement (MI) Factors}

"Male involvement" factors were conceptualized and measured in three domains: (1) Joining study and study activities; (2) Communication about study product use, and (3) Perceived support for product use; through the clinic attendance records and items in the face-to-face male involvement questionnaire described above. Questionnaire items were informed by the parent study instruments, previous qualitative studies done in the region, and through pilot testing with Zimbabwean research staff (male and female) [2, 7, 33-36]. Because the majority of our sample was married with $<2$ lifetime sexual partners and only one current partner, women were asked to respond to the questionnaire regarding their primary male partner.

During initial exploratory analyses, several questionnaire items that measured similar concepts, or that did not show enough variation to be informative (i.e. $99 \%$ answered yes), were eliminated, or were combined with other items to create composite measures. Ultimately we derived 19 male partner involvement factors that measured the three domains of interest. Multicollinearity among these male involvement factors within and across domains was ruled out through the evaluation of Pearson's correlation coefficients $(r<0.80)$. Response options were already dichotomous (yes/no), or were Likert-scaled, and then collapsed into dichotomous or trichotomous responses. The composite measure of male partners presenting at the clinic for testing, waiting or accompanying female participants in domain 1 included questionnaire data plus the male clinic attendance records. No data were collected directly from male partners, as the primary objective of this study was to understand how women's perceptions of male partner support was associated with her own behaviour.

\section{Acceptability and Adherence Outcomes}

The primary outcome of product acceptability was examined separately for the diaphragm and for the gel using a variable from the MIRA main study acceptability questionnaire administered at the study's closing visit: "How would you rate the [diaphragm/gel] overall?": "strongly like, like, dislike, strongly dislike." The highly skewed distribution of the data suggested that the "like" response was used as the default socially desirable neutral response, and few women reported disliking or strongly disliking the products, thus responses were dichotomized as strongly like versus all other responses. The primary outcome for consistent product use was also taken from the acceptability form administered at the closing visit: those that reported using the diaphragm and gel (combined) for every sex act since the start of the study were categorized as "consistent users" and all others as "inconsistent users." We assessed adherence to the combined use of the diaphragm and gel because this was how women were instructed to use the products in the trial. Acceptability of each product was measured separately as the physical properties, product attributes and potential effects on ease of use, sexual pleasure and discreet use were substantially different.

\section{Potential Confounders}

Potential confounders included in bivariate and multivariate analyses were socio-demographic measures of the study participant and her partner, laboratory-confirmed STIs, sexual history and risk behavior of the participant and her partner, as well as contraceptive and disease prevention method use collected through FTF interview or ACASI. In the analysis of consistent use, we also controlled for women's own report of "strongly liking" the diaphragm or gel, measured at the Exit visit through the measure described above.

\section{Analytical Sample and Statistical Considerations}

Mostly because of delays with study initiation, over half of the total study sample $(56.4 \%)$ had only one male involvement assessment, and the remainder $(43.6 \%)$ had two. After confirming among the latter group of women that responses did not differ by more than $5 \%$ for each question, we retained only the last available record for each individual in analysis, resulting in a final analytical sample of 955 women. This study sample was limited to women who were in the intervention arm and received the diaphragm and gel when randomized into the MIRA trial. MI variables within the domains of interest were tabulated, and associations between these factors and the outcomes of product acceptability and consistent use were examined in a three-step process. First, bivariate associations were computed using Chi-square and Cochran-Mantel-Haenszel statistics. Following this, within each conceptual domain, the outcome of interest was regressed against all male involvement variables (results of this intermediate step are not presented). Finally, using those variables that remained significant at the $P<0.10$ level in the "domain-level regression", and significant potential confounders from bivariate analyses, multivariate logistic regression models were constructed, and final models retained independent 
predictors that were statistically significant at the $P<0.05$ level. Automated backwards, forwards and stepwise selection procedures were used to confirm the stability of the final models. For $7.7 \%$ of the study sample, outcomes and exposures were measured at the same time point, rather than exposures preceding the outcomes. This was because a small proportion of women exited the trial at Month 12 (at the time of their male involvement assessment), and some missed their Month 12 visit and did not return to complete their male involvement questionnaire until Exit (and had missed the Month 3 assessment). All analyses were conducted using SAS, version 9.1 (Cary, NC, USA).

\section{Results}

Characteristics of the Study Sample

Our sample of 955 Zimbabwean female participants who were randomized to receive the diaphragm and gel at enrollment is described in Table 1 . The majority of women $(83 \%)$ were under 35 , and partners were slightly older. Just under half of the female participants (48\%) were highschool educated. While only $27 \%$ reported being employed, three-quarters $(76 \%)$ reported earning income in the past year, and $84 \%$ reported that their partners were employed. The vast majority $(97 \%)$ were married, and living with their partner $(97 \%)$. Half the women $(49 \%)$ were HSV-2 positive at baseline and a further $6 \%$ tested positive for chlamydia, gonorrhea, syphilis or trichomoniasis during the screening procedures and were treated prior to enrollment. The majority $(79 \%)$ of the sample were using hormonal contraceptives (pill or injectables). Mean age of sexual debut was 18.6. Just over a quarter (26\%) reported using a condom always in the past 3 months at baseline. We created 2 composite variables of behavioral risk, and $24 \%$ of women were classified as high risk, while $65 \%$ of women had partners with high risk (see Table 1 footnote for definitions).

\section{Male Involvement Factors, Product Acceptability} and Use

The frequencies of male involvement factors, and bivariate associations with the outcomes of "strongly liking" and consistent use of the diaphragm and gel are presented by conceptual domain in Table 2 . At exit, the majority $(89.4 \%)$ of women reported strongly liking the diaphragm, as well as the gel $(81.0 \%)$, however only $58.2 \%$ of the sample reported using the combination of diaphragm and gel for every sex act for the duration of the study (Table 2).
MI in Joining Study and Study Activities

The vast majority of female participants $(96.3 \%)$ reported asking permission from their male partner to join the MIRA study, and $70 \%$ of these women reported that they would face problems at home if they did not first ask permission. The latter factor was associated with strongly liking the diaphragm and gel at the $P<0.10$ level (Table 2). Only about half of the women $(54.7 \%)$ reported that her partner was "very interested" in her study participation, and those that did were more likely to strongly like the gel and be consistent users ( $P<0.01$ for both). There was nearly universal disclosure of HIV/STI results to the male partner $(99.3 \%)$ and discussions/reminders about MIRA study visits was also common (71.2\%). Very few men came to the study clinic: $17.1 \%$ of men reportedly dropped off or met their female partners outside, while a smaller proportion (13.6\%) came to the clinic to test, accompany or wait for their partners (as measured by women's report in the questionnaire and clinic logs).

\section{Communication About Study Product Use}

The majority $(81.6 \%)$ of women reported that either she explicitly told her partner she was using the diaphragm/gel every time she did so, or she perceived that he implicitly knew (Table 2).Thus, only, $10.6 \%$ of participants reported that they intentionally used the diaphragm and gel secretly at least some of the time (also Table 2). Both of these disclosure variables were highly significantly associated with the acceptability and adherence outcomes in bivariate analysis. A high proportion $(88.3 \%)$ reported their partner asked about proper storage and care of the study products or asked if the diaphragm was feeling comfortable.

\section{Perceived Support for Study Product Use}

Despite high support for study participation (97.1\%, domain 1), only $44.9 \%$ of female participants reported that their partner "strongly" supported the idea of using the diaphragm and gel (Table 2). While perceptions of partners' favorability towards the products was rather low, with only $31.4,26.1$ and $24.1 \%$ of women reporting that he "strongly likes" the diaphragm, gel, and condoms respectively, these measures were all highly significantly associated with all outcomes in bivariate analyses (Table 2). Measures of it being "somewhat difficult" or "difficult" to convince the partner to use the diaphragm or condoms were negatively associated with consistent diaphragm and gel use. A small proportion of women (16.0\%) reported that their male partners helped to insert the diaphragm or gel applicators at some point during use. 
Table 1 Baseline characteristics of study sample $(n=955)$

a This category includes 56 women who reported no contraception, 19 who reported withdrawal, and 1 individual each who reported use of: holy water, "traditional methods" or "natural methods"

b At least one indicator vs. none of: any exchange of sex for money, food shelter, 2 or more sexual partners in past

3 months, ever had vaginal sex under the influence of drugs or alcohol in the past 3 months; ever used needle for injectable drug use; ever had anal sex

$c$ At least one indicator vs. none of: female participant having any sexual partners test positive for HIV; suspect or know that regular male partner has had other sex partners in past 3 months; regular male partner was away from home for 1 or more months

\begin{tabular}{|c|c|c|}
\hline & $n$ & $\%$ \\
\hline \multicolumn{3}{|l|}{ Demographic characteristics } \\
\hline \multicolumn{3}{|l|}{ Age } \\
\hline 24 years or younger & 357 & 37.4 \\
\hline $25-34$ & 435 & 45.6 \\
\hline 35 years or older & 163 & 17.1 \\
\hline High school education or more & 457 & 47.9 \\
\hline Earned Income in the past year & 721 & 75.5 \\
\hline Employed & 256 & 26.8 \\
\hline Married & 923 & 96.7 \\
\hline Living with partner & 923 & 96.7 \\
\hline Speak Shona at home & 902 & 94.6 \\
\hline Christian & 799 & 88.6 \\
\hline \multicolumn{3}{|l|}{ Current contraceptive use } \\
\hline Long term & 27 & 2.8 \\
\hline Injectables & 138 & 14.5 \\
\hline Pill & 618 & 64.7 \\
\hline Barrier & 94 & 9.8 \\
\hline Other/none $^{\mathrm{a}}$ & 78 & 8.2 \\
\hline \multicolumn{3}{|l|}{ Sexual behavior characteristics } \\
\hline Age at sexual debut (mean/median years) & 18.6 & \\
\hline Lifetime sexual partners (mean/median number) & $1.3 / 1$ & \\
\hline HSV positive & 470 & 49.3 \\
\hline Positive baseline STI & 61 & 6.4 \\
\hline Has sex 3 times per week or more & 446 & 46.7 \\
\hline History of high risk behavior ${ }^{\mathrm{b}}$ & 224 & 23.5 \\
\hline \multicolumn{3}{|l|}{ Condom use in the past 3 months } \\
\hline Never & 300 & 31.4 \\
\hline Sometimes & 411 & 43.0 \\
\hline Always & 244 & 25.6 \\
\hline Condom use at last sex (enrolment) & 672 & 70.4 \\
\hline \multicolumn{3}{|l|}{ Partner characteristics } \\
\hline Male partner high risk behavior ${ }^{\mathrm{c}}$ & 624 & 65.3 \\
\hline \multicolumn{3}{|l|}{ Partner age } \\
\hline $18-30$ & 355 & 37.2 \\
\hline $31-40$ & 408 & 42.7 \\
\hline $41-50$ & 124 & 13.0 \\
\hline 51 or older & 56 & 5.9 \\
\hline Don't know & 12 & 1.3 \\
\hline Partner employed & 800 & 83.8 \\
\hline
\end{tabular}

\section{Association Between MI Factors and Strongly Liking the Diaphragm and Gel}

In the final multivariate models adjusting for MI factors and potential confounders, several factors were independently associated with "strongly liking" the diaphragm and gel (Table 3). Within the domain of communication about study product use, women who reported never using the diaphragm and gel secretly were more than twice as likely to report strongly liking the diaphragm (AOR 2.69, 95\% CI: 1.64-4.41) as well as strongly liking gel (AOR 2.03, 95\% CI: 1.28-3.24). Women who reported that they told their male partner, or that he knew she was using the products each time were significantly more likely to strongly like the gel (AOR 1.80, 95\% CI: 1.16-2.80), but not diaphragms.

Two other elements of women's perceptions of partner support were also associated with women's acceptability. 
Table 2 Frequencies and bivariate associations between male involvement factors and strongly liking and consistent use of diaphragm and gel $(n=955)$

\begin{tabular}{|c|c|c|c|c|c|c|c|}
\hline & & Stror & diaphragm & Stron & ke gel & $\begin{array}{l}\text { Cons } \\
\text { and } g\end{array}$ & iaphragm \\
\hline$n$ & $\%$ & $806^{\mathrm{a}}$ & $89.4 \%$ & $719^{\mathrm{a}}$ & $81.0 \%$ & $518^{\mathrm{a}}$ & $58.2 \%$ \\
\hline
\end{tabular}

Domain 1: joining study and study activities

She asked permission to join MIRA study

Yes vs. no

She would face problems at home if she did not ask permission first

Yes vs. no

Support for her being in the study

$919 \quad 96.3-1.71$

Supportive/very supportive vs. not supportive

Interest in her study participation

Very interested vs. somewhat or not very interested

She has disclosed STI or HIV results to her partner and/or told him she will be tested for HIV/STIs at MIRA

Yes vs. no

948

She reminds him about her visits every time she goes, and he asks about her visits every time she comes home

Yes vs. no

Partner ever dropped off or met outside clinic

Yes vs. no

Partner ever came to clinic to test, accompany,

or to wait inside

Yes vs. no

90

$54.7-1.35$

$0.20-0.51$

0.28

$0.02-4.89$

1.83

$0.41-8.21$

680

163

$17.1-0.94$

$0.86-2.02$

130

$13.6 \quad 1.04$

$0.57-1.89$

1.27

$0.77-2.09 \quad 0.86$

$0.60-1.25$

Domain 2: communication about product use

Ever used diaphragm or gel secretly

Yes vs. no

Told him or he implicitly knew she was using the diaphragm and gel every time she used it

Yes vs. no

He asked about proper care and storage of diaphragms or condoms, or asked if diaphragm is comfortable/ fitting correctly

Yes vs. no

Domain 3: support/perception of support for product use

He helped to insert diaphragm or gel applicator

Yes vs. no

93

$10.6 \quad 0.32 * *$

$0.20-0.51$

$0.34 * *$

$0.23-0.51$

$0.47^{* *}$

$0.32-0.68$

779

$81.62 .23 * *$

$1.43-3.50$

$2.40 * *$

$1.66-3.47$

$2.59^{* *}$

$1.85-3.63$

84

$843 \quad 88.3 \quad 0.86$

14

$\begin{array}{ll}16.0 & 0.77\end{array}$

$0.46-1.29$

1.02

$0.65-1.60 \quad 0.73^{*}$

$0.52-1.04$

His support for the idea of using diaphragm and gel

Strongly supports vs. somewhat or does not support

Difficulty in convincing partner to use diaphragm

Somewhat difficult or difficult vs. not at all difficult

Difficulty in convincing partner to use condoms

Somewhat difficult or difficult vs. not at all difficult

Partner's attitude towards diaphragm

Strongly likes vs. like, dislike, strongly dislike

42

$44.9 \quad 1.52 *$

$0.99-2.32$

$1.80 * *$

$1.28-2.53 \quad 1.54 * *$

$1.18-2.00$

781

84.0

$0.34-0.90$

0.54

$0.36-0.81 \quad 0.53^{* *}$

$0.38-0.76$

$\begin{array}{lll}709 & 74.8 & 0\end{array}$

$0.41-0.97$

0.74

$0.52-1.05$

$0.58 * *$

$0.43-0.78$

$292 \quad 31.4 \quad 4.19 * *$

$2.20-7.96$

$2.30 * *$

$1.53-3.46 \quad 2.63 * *$

$1.95-3.56$

Partner's attitude towards gel

Strongly likes vs. like, dislike, strongly dislike

Partner's attitude towards condoms

Strongly likes vs. like, dislike, strongly dislike
243

$229 \quad 24.1 \quad 2.65^{* *} \quad 1.42-4.93$

$1.67-6.04$
$2.02 * *$

$1.32-3.10 \quad 2.50 * *$

$1.81-3.44$

$1.70 * * \quad 1.11-2.58 \quad 2.34 * *$

${ }^{\text {a }}$ Denominator does not equal 955 because of missing data for exposure variables in some observations

* Variable significant at $P=0.01-0.10$ level

** Variable significant at $P<0.01$ level 
Women who reported that their partners "strongly liked" the diaphragm were over three times as likely (AOR 3.45, 95\% CI: 1.80-6.63) to report strongly liking the diaphragm themselves and almost twice as likely to report the same for gel (AOR 1.79, 95\% CI: 1.18-2.73).

\section{Association Between MI Factors and Consistent Use of the Diaphragm and Gel}

In the final multivariate model of male involvement factors and women's consistent use of the products (Table 3), communication was also important: women who reported telling their partner about diaphragm and gel use every time they had sex (or he knew implicitly) were more than twice as likely to consistently use those products (AOR 2.28, 95\% CI: 1.55-3.35). Women who reported they would "face problems at home" if they did not first ask permission to join the study - a proxy measure of relationship control and harmony-were less likely to be consistent users (AOR 0.70, 95\% CI: 0.51-0.96).

A woman's own report that she "strongly liked" the diaphragm was significantly associated with consistent use (AOR 3.51, 95\% CI: 2.16-5.71); furthermore, her perception of her partner's strong liking of the diaphragm was also independently associated with consistent use (AOR 2.27, 95\% CI: 1.64-3.15). Women who reported at baseline that they used a condom the last time they had sex were more likely to be consistent diaphragm and gel users (AOR 1.45, 95\% CI: 1.07-1.98). Finally, women over 35 were more likely to be consistent diaphragm and gel users, and the likelihood of using products consistently decreased with younger age group categories (Table 3 ).

\section{Discussion}

This is the first study to measure how female participants in a large trial of female-initiated HIV prevention methods chose to involve their male partners, and the first to attempt to measure an association between measures of male partner involvement and product acceptability and adherence in such a study. Our hypothesis, which was confirmed, was that female study participant's behaviors and decisionmaking in a patriarchal setting such as Zimbabwe, were influenced by the attitudes and actions-whether perceived or actual-of her male partner, even though the investigational products were meant to be "female-initiated".

By better understanding the role of the male partner on women's participation and behaviors in a HIV prevention trial, and assessing his influence, we can devise appropriate HIV prevention strategies that adapt to these socio-cultural realities. "Male involvement" is sometimes narrowly

Table 3 Multivariate associations between male involvement factors and strongly liking and consistent use of diaphragm gel

\begin{tabular}{|c|c|c|c|c|c|c|}
\hline \multirow[t]{2}{*}{ Male involvement factors } & \multicolumn{2}{|c|}{$\begin{array}{l}\text { Strongly like diaphragm } \\
(n=902)\end{array}$} & \multicolumn{2}{|c|}{ Strongly like gel ${ }^{\mathrm{b}}(n=888)$} & \multicolumn{2}{|c|}{$\begin{array}{l}\text { Consistent diaphragm } \\
\text { and gel use }{ }^{c}(n=890)\end{array}$} \\
\hline & AOR & $95 \% \mathrm{CI}$ & AOR & $95 \% \mathrm{CI}$ & AOR & $95 \% \mathrm{CI}$ \\
\hline \multicolumn{7}{|l|}{ Joining study and study activities } \\
\hline Would face problems if she didn't ask permission & NS & & NS & & 0.70 & $0.51-0.96$ \\
\hline \multicolumn{7}{|l|}{ Communication about product use } \\
\hline Never used secretly & 2.69 & $1.64-4.41$ & 2.03 & $1.28-3.24$ & NS & \\
\hline Told him or he knew every time & NS & & 1.80 & $1.16-2.80$ & 2.28 & $1.55-3.35$ \\
\hline \multicolumn{7}{|l|}{ Perceptions of support for product use } \\
\hline Partner strongly likes diaphragm & 3.45 & $1.80-6.63$ & 1.79 & $1.18-2.73$ & 2.27 & $1.64-3.15$ \\
\hline \multicolumn{7}{|l|}{ Potential confounders } \\
\hline Age $(<24$ vs. 35 or older $)$ & - & & - & & 0.47 & $0.30-0.72$ \\
\hline Age $(25-34$ vs. 35 or older $)$ & - & & - & & 0.61 & $0.40-0.94$ \\
\hline Condom used at last sex (at enrolment visit) & - & & NS & & 1.45 & $1.07-1.98$ \\
\hline She strongly likes diaphragm & - & & - & & 3.51 & $2.16-5.71$ \\
\hline
\end{tabular}

$N S$ variable included, but not significant, in final model; “-” variable not significant in bivariate and domain-level analysis and not included in final model

a Controlling for: would face problems if permission not asked to join study, consistent disclosure of product use, perceived support for diaphragm and gel use, partner strongly liking gel, partner strongly liking condoms, education

${ }^{\mathrm{b}}$ Controlling for: would face problems if permission not asked to join study, perceived partner interest in study, perceived support for diaphragm and gel use, partner strongly liking gel, partner strongly liking condoms, education, religion, condom used at last sex (at baseline)

${ }^{c}$ Controlling for: never used diaphragm and gel secretly, partner ever helped insert applicator or diaphragm, partner strongly likes condoms, education, coital frequency, baseline HSV-2 status, condom use in the last 3 months (at enrolment visit), partner's employment status, perception of partner's fidelity, partner's age category 
defined as the physical participation of men in study activities, or his physical presence/accompaniment to the clinic [37]. Here, we also assessed several measures of partner communication and support that extended beyond attendance, to better understand those aspects of "male involvement" which are salient to women's attitudes and behaviour. While several of the variables we examined may appear conceptually linked, i.e. if a woman reports that he was supportive of her participation in the study, one might expect he was also interested in it, we took several measures to rule out collinearity through examination of correlation matrices, and the inclusion of an intermediate step between the bivariate analyses and the final multivariate models in which the outcome was regressed against individual items within each domain, which lends insight into the complex nuances of male partner involvement.

This study identified three key findings about male partner involvement in women's clinical trial participation and the use of female-initiated methods for disease prevention. First the majority of female study participants involved their partners largely by: (a) requesting permission of their primary male partners to join the study; (b) involving their partner in the routine aspects of the study including test results disclosure and visit reminders, and (c) notifying them regularly about use of the diaphragm and gel. Other smaller and shorter studies of female-initiated methods have also reported high levels of partner communication, where women almost universally disclose participation and use of products to their partners, despite the fact that the investigational products - whether diaphragms or gels - could be used without partner knowledge [2, 10, 35]. Our findings also support previous qualitative work in the region where women and male partners have discussed the importance of involving the male partner in the research study process $[33,34,38]$. Only about $10 \%$ of women reported ever using the diaphragm and gel secretly, and a smaller proportion did so consistently throughout the study [39].

Here, we didn't specifically explore the motivation for women's decision to involve her male partner. However, our qualitative data and the finding that approximately $70 \%$ of women reported that would "face problems at home" if they did not first ask permission to join the study suggest that a major impetus is rooted in a fear of negative consequences if the male partner was not involved [39]. This interpretation is corroborated by other qualitative work indicating that men in Zimbabwe want to remain the "decision-makers" in matters of reproductive health [2].

Secondly, women who openly reminded their partner, or whose partners knew she was using the diaphragm and gel every time were significantly more likely to strongly like, and consistently use both products. Similarly, those who never used them secretly were more likely to report strongly liking the diaphragm and gel. These results corroborate, in part, the findings of a 6-month diaphragm acceptability study in Zimbabwe among 186 women, where women who either always or never disclosed use were significantly more likely to be consistent diaphragm users [10]. As has been discussed previously, disclosure of product use and discrete use is a nuanced continuum where partners' knowledge of product use might range from complete awareness at each episode, to implied use (i.e. male partner knows in general that his partner is using the diaphragm, but she does not tell him at every act of sex), to occasional covert use, to complete covert use [39, 40]. Our findings suggest that open and successful dialogue about product use with partners-both in terms of disclosure and negotiation for use-enhance women's acceptability and use of the products in a trial setting.

Our third key finding is that when women perceived that their male partners strongly liked the study products they were also more likely to strongly like and use them. This has been reported in smaller studies in the region, and a study in the United States among diaphragm-users [41, 42]. It is perhaps intuitive that if one member of a sexual dyad felt strongly in either direction about the use of a contraceptive or disease prevention method, this would be likely to influence the other member. However, in this and other studies of female-initiated HIV prevention methods, acceptability is often assessed as the female study participant's attitudes, and/or her perception of her partner's attitudes, with little to no measurement of whether and how her attitudes might change or affect her partner's, and vice versa. Although we were able to independently assess whether the women's own strong liking of a product, and her perception of her partners liking the product were independently associated with consistent use, we could not disentangle the interdependent effect of one partner's attitudes and behaviors on the other.

So as to better capture the effect of one partner's attitude on the other, future research with women in stable partnerships should use study designs that incorporate the couple as well as more sophisticated measurements and analytical techniques that capture the interdependence of attitudes and behaviors between partners. Although potentially resource-intensive, enrolling discordant couples may be the most effective and efficient means of gaining male partner support for product use, measuring male partner influence, and assessing efficacy of an investigational product for the prevention of heterosexual HIV transmission in women. While the recently completed Partners in Prevention study demonstrated that enrolling large numbers of serodiscordant couples is feasible [43], other less-intensive approaches to involving male partners in women's prevention trials could also be considered, for example study teams might offer couples counseling and information sessions for men to encourage open 
partner-communication and approval for investigational products; and present various techniques for initiating conversations such as role-playing exercises. The effort to involve men in such interactions might empower them to be more positively involved in their female partner's health in general and specifically, more supportive of protocol activities. Sessions could further provide venues to address concerns and highlight potentially positive aspects of product characteristics, such as enhanced lubrication and sexual pleasure.

There are a number of potential limitations in this study. The first is related to the inherent difficulty in defining and quantifying "male involvement", as no set standard exists. We measured several different types of male involvement, but the positive or negative nature of each aspect of involvement was not quantified. Further, while we broadened our conceptual definition of male partner involvement from physical presence in the clinic to include such concepts as women's perceptions of her partner's support and effective couples communication, we only focused on the primary male partner, and this limits the generalizability of our findings.

The second limitation is potential selection biasbecause the sample is comprised of women who have opted (or been allowed) to join a clinical trial to begin with, they may be different from women in the general community in significant ways, and particularly with regard to their partnerships. Women who enrolled in the study may be in partnerships with inherently more cooperative partners with whom more open communication can occur compared to women who do not (or cannot) participate. Of note, the majority of this population was married (97\%) and had less than 2 lifetime sexual partners. In light of these first two limitations, an important consideration for future research is how "male involvement" would influence different subpopulations of women (i.e. commercial sex workers, unmarried women, widows); women in different cultural settings and in regards to different partnership types (casual partners vs. husbands vs. clients, both serially and concurrently). In addition, participants that were classified as lost-to follow-up (LTFU) were not included in this analysis, and reasons for LTFU may have been partner-related. This bias was minimized by our overall retention rate of $96 \%$, and our inclusion of Month 3 data for those that did not have a Closing visit. A third limitation is that the exposure and outcome variables for this study are based on self-reported data collected through interviewer-administered questionnaires, and subject to both recall and social desirability biases. The latter may have been partially overcome through use of a more confidential data collection modality, such as ACASI. However, we knew from previous analyses that the adherence outcome measure used here (collected face-to-face) yielded almost identical results to our ACASI data on consistent product use throughout the trial $[32,44]$. Further, because of the way in which the data were collected, we were able to assess the effect of male involvement on women's acceptability of the diaphragm or gel, and on use of the products in combination, but unable to measure how MI was associated with acceptability of the combination product, or use of the products individually. These measures may have yielded different results, and future studies of combination products should measure acceptability and use of all components individually and in combination.

As with all studies, there may be other confounding factors not measured, considered or controlled for in this analysis. Importantly, it should also be noted that in this study, the products evaluated were coitally-dependent which may have necessitated more dialogue and disclosure of use with the male partner. Other coitally independent approaches, such as diaphragms worn continuously, vaginal rings or daily insertion of gels, are currently under investigation; such methods will undoubtedly have an effect on the nature of male involvement and level of discussion between partners.

Potentially the most significant limitation is that we measured male involvement from the perspective of the women only. Although this may seem counterintuitive in a study about men, we were interested in women's attitudes and behaviours as influenced by her perceptions of her partner, irrespective of the accuracy of these perceptions. Even if a male partner had told us he was very supportive of diaphragm use, his partner might not know or perceive this to be true, and would act in response to her own beliefs. Finally, because this study was nested within a clinical trial it was not possible to explore the effect of an intervention to promote male involvement on women's behaviour. To measure such an effect, it would be ideal to offer a male partner intervention in a randomized design.

However, because there was no formalized intervention or procedure to involve male partners, not surprisingly, only a small proportion of partners came to the clinic: $13.6 \%$ came inside to wait or have services, $17.1 \%$ dropped off or met her outside. Clearly we had too little power to detect the effect of bringing men to the clinic on women's behavioral outcomes, however, it is also possible that encouraging men to be involved by the commonly discussed strategy of inviting them to attend a clinic visit is not efficacious. Qualitative data from this study suggest that an important barrier for men coming to the study clinic was the perception that they would have to learn their HIV status, and that this information might be shared with their female partner. There is a paucity of evidence-based strategies to effectively engage male partners in women's health research, particularly those in which HIV testing and novel female-initiated methods are introduced. 
In conclusion, this study confirmed that even in the context of a clinical trial of a female-initiated HIV prevention method in Zimbabwe, male partners play a critical role in women's discussions and decisions regarding joining the study, study activities, test results and investigational product use. Women's report of full disclosure of study product use and partner approval for products were significantly associated with their acceptability and consistent use; an essential component of determining the efficacy of an investigational prevention method. Our results also support the need for more sophisticated measurement of how couples interact to make decisions that affect study-related behaviors as well as more concerted efforts to encourage male partner involvement in femalerelated HIV prevention trials. Mandatory counseling or education sessions with male partners and/or couples, or even couples-based enrollment should be important considerations for future studies.

Acknowledgments We would first and foremost like to acknowledge the women who participated in this study. In addition, we are indebted to the efforts of the administrative and data coordination staff at the University of California, San Francisco; and staff at Ibis Reproductive Health; The University of Zimbabwe-University of California, San Francisco Collaborative Research Programme; the Medical Research Council, HIV Prevention Research Unit (Durban); and Perinatal HIV Research Unit of the University of the Witwatersrand. ET Montgomery was the Principal Investigator for the Male Involvement study and the Protocol Director for the MIRA Study, wrote the majority of the paper, and conducted the analysis for this manuscript. A. van der Straten was the co-principal investigator of MIRA and provided scientific guidance and interpretation on this study and the analysis. A. Chidanyika was the Project Director at the research sites and reviewed and edited each draft of the manuscript. T. Chipato was the Site Investigator for MIRA at the University of Zimbabwe and provided overall guidance to the study, and reviewed each draft of this manuscript. S. Jaffar was the PhD Supervisor to ET Montgomery, and provided scientific guidance on the development of the project, analysis and interpretation of findings. He reviewed each version of the manuscript. N. Padian was the overall MIRA trial principal investigator and provided scientific leadership in the analysis and presentation of this paper, and reviewed and edited each draft. For E.T. Montgomery, A. van der Straten and N. Padian most work for this study was conducted at the University of California San Francisco, Department of Obstetrics, Gynecology and Reproductive Sciences.

This research was funded by the Bill and Melinda Gates Foundation.

Open Access This article is distributed under the terms of the Creative Commons Attribution Noncommercial License which permits any noncommercial use, distribution, and reproduction in any medium, provided the original author(s) and source are credited.

\section{References}

1. UNAIDS. Report on the global AIDS epidemic: executive summary. Geneva; 2008.

2. Buck J, Kang MS, van der Straten A, Khumalo-Sakutukwa G, Posner S, Padian N. Barrier method preferences and perceptions among Zimbabwean women and their partners. AIDS Behav. 2005;9(4):415-22.

3. Woodsong C, Alleman P. Sexual pleasure, gender power and microbicide acceptability in Zimbabwe and Malawi. AIDS Educ Prev. 2008;20(2):171-87.

4. UNFPA, editor. Programme of action. International Conference on Population and Development. Cairo, Egypt: UNFPA; 2004.

5. UN Division for the Advancement of Women, editor. Platform for action. United National Fourth World Conference on Women. Beijing, China; 1995.

6. ACOG. Partner consent for participation in women's reproductive health research. Obstet Gynecol. 2004;104(6):1467-9.

7. Green G, Pool R, Harrison S, Hart GJ, Wilkinson J, Nyanzi S, et al. Female control of sexuality: illusion or reality? Use of vaginal products in south west Uganda. Soc Sci Med. 2001;52(4): 585-98.

8. Bulut A, Ortayli N, Ringheim K, Cottingham J, Farley TM, Peregoudov A, et al. Assessing the acceptability, service delivery requirements, and use-effectiveness of the diaphragm in Colombia, Philippines, and Turkey. Contraception. 2001;63(5):267-75.

9. Ortayli N, Bulut A, Nalbant H, Cottingham J. Is the diaphragm a viable option for women in Turkey? Int Fam Plan Perspect. 2000;26(1):36-42.

10. van der Straten A, Kang M, Posner SF, Kamba M, Chipato T, Padian NS. Predictors of diaphragm use as a potential sexually transmitted disease/HIV prevention method in Zimbabwe. Sex Transm Dis. 2005;32(1):64-71.

11. Pool R, Whitworth JA, Green G, Mbonye AK, Harrison S, Wilkinson J, et al. An acceptability study of female-controlled methods of protection against HIV and STDs in south-western Uganda. Int J STD AIDS. 2000;11(3):162-7.

12. Mbizvo M, Adamchak DJ. Family planning knowledge, attitudes, and practices of men in Zimbabwe. Stud Fam Plan. 1991;22(1): 31-8.

13. Orubuloye IO, Caldwell JC, Caldwell P. African women's control over their sexuality in an era of AIDS. A study of the Yoruba of Nigeria. Soc Sci Med. 1993;37(7):859-72.

14. (ZWRCN) ZWsRCaN. Gender and HIV/AIDS: an analysis of Zimbabwe's national policies and programs on HIV/AIDS/STIs. Harare: Zimbabwe Women's Resource Centre and Network (ZWRCN); 2003.

15. Mbizvo M, Bassett M. Reproductive health and AIDS prevention in sub-Saharan Africa: the case for increased male participation. Health Policy Plan. 1996;11(1):84-92.

16. Piotrow P, Kincaid L, Hindin M, Lettenmaier C, Kuseka I, Silberman T, et al. Changing men's attitudes and behavior: the Zimbabwe Male Motivation Project. Stud Fam Plan. 1992;23(6): 365-75.

17. Campbell C. Male gender roles and sexuality: implications for women's AIDS risk and prevention. Soc Sci Med. 1995;41(2): 197-210.

18. Wang CC, Vittinghoff E, Hua LS, Yun WH, Rong ZM. Reducing pregnancy and induced abortion rates in China: family planning with husband participation. Am J Public Health. 1998;88(4): 646-8.

19. Terefe A, Larson C. Modern contraception use in Ethiopia: does involving husbands make a difference? Am J Public Health. 1993;83(11):1567-71.

20. Farquhar C, Kiarie JN, Richardson BA, Kabura MN, John FN, Nduati RW, et al. Antenatal couple counseling increases uptake of interventions to prevent HIV-1 transmission. J Acquir Immune Defic Syndr. 2004;37(5):1620-6.

21. Coates TJ, Grinstead OA, Gregorich SE, Sweat MD, Kamenga MC, Sangiwa G, et al. Efficacy of voluntary HIV-1 counselling and testing in individuals and couples in Kenya, Tanzania, and Trinidad: a randomised trial. Lancet. 2000;356(9224):103-12. 
22. Padian NS, Obrien TR, Chang YC, Glass S, Francis DP. Prevention of heterosexual transmission of human immunodeficiency virus through couple counseling. J Acquir Immune Defic Syndr. 1993;V6(N9):1043-8.

23. Allen S, Meinzen-Derr J, Kautzman M, Zulu I, Trask S, Fideli U, et al. Sexual behavior of HIV discordant couples after HIV counseling and testing. AIDS. 2003;17(5):733-40.

24. Jones DL, Ross D, Weiss SM, Bhat G, Chitalu N. Influence of partner participation on sexual risk behavior reduction among HIVpositive Zambian women. J Urban Health. 2005;82(3, Suppl 4): iv92-100.

25. El-Bassel N, Witte S, Gilbert L, Wu E, Chang M, Hill J, et al. The efficacy of a relationship-based HIV/STI prevention program for heterosexual couples. Am J Public Health. 2003;93(6):963-9.

26. El-Bassel N, Witte S, Gilbert L, Wu E, Chang M, Hill J, et al. Long-term effects of an HIV/STI sexual risk reduction intervention for heterosexual couples. AIDS Behav. 2005;9(1):1-13.

27. Pulerwitz J, Gortmaker SL, DeJong W. Measuring sexual relationship power in HIV/STD research. Sex Roles. 2000;42(7-8): 637-60.

28. Dunkle K, Jewkes R, Brown H, Gray G, McIntyre J, Harlow S. Gender-based violence, relationship power and risk of HIV infection in women attending antenatal clinics in South Africa. Lancet. 2004;363:1415-21.

29. Pettifor AE, Measham DM, Rees HV, Padian N. Sexual power and HIV risk, South Africa. Emerg Infect Dis. 2004;10(11): 1996-2004.

30. Sternberg P, Hubley J. Evaluating men's involvement as a strategy in sexual and reproductive health promotion. Health Promot Int. 2004;19(3):389-96.

31. Mullany B, Hindin M, Becker S. Can women's autonomy impede male involvement in pregnancy health in Katmandu, Nepal? Soc Sci Med. 2005;61(2005):1993-2006.

32. Padian NS, van der Straten A, Ramjee G, Chipato T, de Bruyn G, Blanchard K, et al. Diaphragm and lubricant gel for prevention of HIV acquisition in southern African women: a randomised controlled trial. Lancet. 2007;370(9583):251-61.

33. Moon M, Msizvo M, Heiman J, et al. Evaluation of the feasibility and acceptability of vaginal microbicides for the prevention of HIV/STI in Zimbabwe. Natl Acad Pract Forum. 2000;2:135-9.

34. van de Wijgert JHHM, Khumalo-Sakutukwa GN, Coggins C, Dube SE, Nyamapfeni P, Mwale M, et al. Men's attitudes toward vaginal microbicides and microbicide trials in Zimbabwe. Int Fam Plan Perspect. 1999;25(1):15-20.

35. Pool R, Hart G, Green G, Harrison S, Nyanzi S, Whitworth J. Men's attitudes to condoms and female controlled means of protection against HIV and STDs in south-western Uganda. Cult Health Sex. 2000;2(2):197-211.

36. Coggins C, Blanchard K, Friedland B. Men's attitudes towards a potential vaginal microbicide in Zimbabwe, Mexico and the USA. Reprod Health Matters. 2000;8(15):132-41.

37. Maman S. Redefining male involvement in prevention of mother to child transmission (PMTCT) from female partner's perspectives. IAS MExico City Conference Oral Presentation THAC0406. 2008.

38. Moon MW, Khumalo-Sakutukwa GN, Heiman JE, Mbizvo MT, Padian NS. Vaginal microbicides for HIV/STI prevention in Zimbabwe: what key informants say. J Transcult Nurs. 2002; 13(1):19-23.

39. Sahin-Hoduglugil N, Van der Straten A, Cheng H, Montgomery E, Kacanek D, Mtetwa S, et al. Degrees of disclosure: a study of women's covert use of the diaphragm in MIRA, an HIV prevention trial in sub-Saharan Africa. Soc Sci Med. 2009;69(10): 1547-55.

40. Kang MS, Buck J, Padian N, Posner SF, Khumalo-Sakutukwa G, van der Straten A. The importance of discreet use of the diaphragm to Zimbabwean women and their partners. AIDS Behav. 2007;11(3):443-51.

41. van der Straten A, Moore J, Napierala S, Clouse K, Mauk C, Hammond $\mathrm{N}$, et al. Consistent use of a combination product versus a single product in a safety trial of the diaphragm and microbicide in Harare, Zimbabwe. Contraception. 2008;77(6):435-43.

42. Beckman LJ, Harvey SM, Thorburn S, Maher JE, Burns KL. Women's acceptance of the diaphragm: the role of relationship factors. J Sex Res. 2006;43(4):297-306.

43. Lingappa JR, Kahle E, Mugo N, Mujugira A, Magaret A, Baeten $\mathrm{J}$, et al. Characteristics of HIV-1 discordant couples enrolled in a trial of HSV-2 suppression to reduce HIV-1 transmission: the Partners Study. PLoS ONE. 2009;4(4):e5272. doi:10.1371/ journal.pone.0005272.

44. van der Straten A, Shiboski S, Montgomery E, Moore J, Bruyn G. Patterns and predictors of adherence to diaphragm use in a Phase III trial in sub-Saharan Africa: a trajectory analysis. J Acquir Immune Defic Syndr. 2009;50(4):419-26. 